Lecture Notes in Computer Science

1905

Edited by G. Goos, J. Hartmanis and J. van Leeuwen 
Springer

Berlin

Heidelberg

New York

Barcelona

Hong Kong

London

Milan

Paris

Singapore

Tokyo 
Hans Scholten Marten J. van Sinderen (Eds.)

\section{Interactive Distributed \\ Multimedia Systems and Telecommunication Services}

7th International Workshop, IDMS 2000

Enschede, The Netherlands, October 17-20, 2000 Proceedings

Springer 


\section{Series Editors}

Gerhard Goos, Karlsruhe University, Germany

Juris Hartmanis, Cornell University, NY, USA

Jan van Leeuwen, Utrecht University, The Netherlands

\section{Volume Editors}

Hans Scholten

Marten J. van Sinderen (CTIT)

Department of Computer Science

University of Twente

P.O. Box 217, 7500 AE Enschede, The Netherlands

E-mail: $\{$ scholten,sinderen\}@cs.utwente.nl

Cataloging-in-Publication Data applied for

Die Deutsche Bibliothek - CIP-Einheitsaufnahme

Interactive distributed multimedia systems and telecommunication services : 7th international workshop ; proceedings / IDMS 2000, Enschede, The Netherlands, October 17 - 20, 2000. Hans Scholten ; Marten J. van Sinderen (ed.). - Berlin ; Heidelberg ; New York ; Barcelona ; Hong Kong ; London ; Milan ; Paris ; Singapore ; Tokyo : Springer, 2000

(Lecture notes in computer science ; Vol. 1905)

ISBN 3-540-41130-5

CR Subject Classification (1998): H.5.1, C.2, H.4, H.5, H.3

ISSN 0302-9743

ISBN 3-540-41130-5 Springer-Verlag Berlin Heidelberg New York

This work is subject to copyright. All rights are reserved, whether the whole or part of the material is concerned, specifically the rights of translation, reprinting, re-use of illustrations, recitation, broadcasting, reproduction on microfilms or in any other way, and storage in data banks. Duplication of this publication or parts thereof is permitted only under the provisions of the German Copyright Law of September 9, 1965, in its current version, and permission for use must always be obtained from Springer-Verlag. Violations are liable for prosecution under the German Copyright Law.

Springer-Verlag Berlin Heidelberg New York

a member of BertelsmannSpringer Science+Business Media GmbH

(C) Springer-Verlag Berlin Heidelberg 2000

Printed in Germany

Typesetting: Camera-ready by author, data conversion by PTP-Berlin, Stefan Sossna

Printed on acid-free paper $\quad$ SPIN: $10722662 \quad 06 / 3142 \quad 543210$ 


\section{Preface}

The first International Workshop on Interactive Distributed Multimedia Systems and Telecommunication Services (IDMS) was organized by Prof. K. Rothermel and Prof. W. Effelsberg, and took place in Stuttgart in 1992. It had the form of a national forum for discussion on multimedia issues related to communications. The succeeding event was "attached" as a workshop to the German Computer Science Conference (GI Jahrestagung) in 1994 in Hamburg, organized by Prof. W. Lamersdorf. The chairs of the third IDMS, E. Moeller and B. Butscher, enhanced the event to become a very successful international meeting in Berlin in March 1996.

This short overview on the first three IDMS events is taken from the preface of the IDMS'97 proceedings (published by Springer as Lecture Notes in Computer Science, Volume 1309), written by Ralf Steinmetz and Lars Wolf. Both, Ralf Steinmetz as general chair and Lars Wolf as program chair of IDMS'97, organized an excellent international IDMS in Darmstadt.

Since 1998, IDMS has moved from Germany to other European cities to emphasize the international character it had gained in the previous years. IDMS 98 was organized in Oslo by Vera Goebel and Thomas Plagemann at UniK - Center for Technology at Kjeller, University of Oslo. Michel Diaz, Phillipe Owezarski, and Patrick Sénac successfully organized the sixth IDMS event, again outside Germany. IDMS'99 took place in Toulouse at ENSICA. IDMS 2000 continued the tradition and was hosted in Enschede, the Netherlands.

The goal of the IDMS series of workshops has been and still is to bring together researchers, developers, and practitioners from academia and industry; and to provide a forum for discussion, presentation, and exploration of technologies and advances in the broad field of interactive distributed multimedia systems and telecommunication services, ranging from basic system technologies such as networking and operating system support to all kinds of teleservices and distributed multimedia applications. To accomplish this goal IDMS remains relatively "small": it has no parallel sessions and a limited number of participants to encourage interaction and discussion.

Although IDMS2000 had tough competition from other conferences and workshops, it received 60 submissions from Europe, Asia, Africa, and North and South America. Every paper was refereed by at least three reviewers. A tedious job, luckily made easier with help from the excellent online conference tool ConfMan, developed in Oslo for the 1998 IDMS workshop. Ultimately, the 26 members of the program committee (PC) and 33 referees selected 24 high quality papers for presentation at the workshop. The main topics of IDMS2000 are: efficient audio/video coding and delivery, multimedia conferencing, synchronization and multicast, communication, control and telephony over IP networks, QoS models and architectures, multimedia applications and user aspects, design and implementation approaches, and mobile multimedia and ubiquitous computing systems. This technical program is complemented with three invited papers: "Energy-efficient hand-held multimedia systems" by Gerard Smit, "Short-range connectivity with Bluetooth" by Jaap Haartsen and "On the failure of middleware to support multimedia applications" by Gordon Blair. 
The co-chairs are very grateful for the help they received to make IDMS2000 a successful event. We thank the steering committee for their trust in us to continue the tradition of the IDMS series of workshops, and the PC and referees for the time and effort in selecting the papers for the technical program. We heeded the good advice of the organizers of the previous two workshops Thomas Plagemann, Vera Goebel, Michel Diaz, Philippe Owezarski, and Patric Sénac. Also we would like to acknowledge the cooperation with ACM SIGCOMM and ACM SIGMM, the financial support from KPN Research, Lucent Technologies and Philips, and the financial and organizational support from the Department of Computer Science and CTIT of the University of Twente. Finally, we especially would like to thank the people from the local organization for their help, Marloes Castanada Schlie, Nikolay Diakov, Cléver Guareis de Farias, and Johan Kunnen.

July 2000

Hans Scholten

Marten van Sinderen 


\section{Organization}

\section{Program Co-Chairs}

Hans Scholten, University of Twente, The Netherlands

Marten van Sinderen, University of Twente, The Netherlands

\section{Program Committee}

H. Batteram, Lucent Technologies, The Netherlands

G. v. Bochmann, University of Montreal, Canada

P. Bosch, CWI, The Netherlands

B. Butscher, GMD-FOKUS, Germany

A. Campbell, Colombia University, USA

L. Delgrossi, University of Piacenza, Italy

M. Diaz, LAAS-CNRS, France

H. Eertink, Telematica Instituut, The Netherlands

W. Effelsberg, University of Mannheim, Germany

F. Eliassen, University of Oslo, The Netherlands

L. Ferreira Pires, University of Twente, The Netherlands

V. Goebel, University of Oslo, UniK, Norway

T. Helbig, Philips, Germany

D. Hutchison, Lancaster University, Great Brittain

P. Jansen, University of Twente, The Netherlands

W. Kalfa, TU Chemnitz, Germany

E. Moeller, GMD-FOKUS, Germany

K. Nahrstedt, University of Illinois, USA

P. Owezarski, LAAS-CNRS, France

S. Pink, SICS, Sweden

T. Plagemann, University of Oslo, UniK, Norway

D. Quartel, University of Twente, The Netherlands

P. Sénac, ENSICA, France

G. Smit, University of Twente, The Netherlands

R. Steinmetz, TU Darmstadt / GMD, Germany

L. Wolf, University of Karlsruhe, Germany

\section{Local Organization}

Marloes Castaneda Schlie, University of Twente, The Netherlands

Nikolay Diakov, University of Twente, The Netherlands

Cléver R. Guareis de Farias, University of Twente, The Netherlands

Johan Kunnen, University of Twente, The Netherlands 


\section{Referees}

H. Batteram

C. Kuhmuench

T. Becker

J. Kunnen

P. Berthou

M. Lijding

G. v. Bochmann

K. Lund

P. Bosch

D. Makaroff

B. Butscher

M. Mauve

A. Campbell

E. Meeuwissen

C. Chassot

E. Michiels

R. Denda

E. Moeller

N. Diakov

K. Nahrstedt

M. Diaz

J. Dittrich

P. Owezarski

K.-P. Eckert

T. Plagemann

H. Eertink

A. Pras

W. Effelsberg

D. Quartel

F. Eliassen

R. Roth

L. Ferreira Pires

P. Sénac

C. Fuhrhop

G. Smit

N. Georganas

R. Song

S. Gjessing

R. Steinmetz

D. Thie

V. Goebel

L. Tionardi

C. R. Guareis de Farias

G. Tuquerres

B. Hafskjold

J. Vogel

X. He

C. Wang

T. Helbig

J. Widmer

D. Hutchison

V. S. Wold Eide

P. Jansen

L. Wolf

W. Kalfa

W. Yu

T. Kristensen

\section{IDMS Steering Committee}

Michel Diaz, LAAS-CNRS, France

Vera Goebel, Univ. of Oslo, UniK - Center for Technology at Kjeller, Norway

Eckhard Moeller, GMD-FOKUS, Germany

Thomas Plagemann, Univ. of Oslo, UniK - Center for Technology at Kjeller, Norway Patrick Sénac, ENSICA, France

Lars Wolf, Universität Karlsruhe (TH), Institute for Telematics, Germany

\section{Supporting and Sponsoring Organizations}

$\begin{array}{ll}\text { ACM SIGCOMM } & \text { UT, Computer Science } \\ \text { ACM SIGMM } & \text { UT, CTIT }\end{array}$

KPN Research

Lucent Technologies

Philips 


\section{Table of Contents}

\section{Invited Presentation}

Energy-Efficient Hand-Held Multimedia Systems ................................................... 1

Gerard J.M. Smit

\section{Efficient Audio/Video Coding and Delivery}

Realisation of an Adaptive Audio Tool.... 3

Arnaud Meylan and Catherina Boutremans

A Robust JPEG Coder for a Partially Reliable Transport Service. 14

Johan Garcia and Anna Brunstrom

A Dynamic RAM Cache for High Quality Distributed Video.

Nicolas J.P. Race, Daniel G. Waddington, and Doug Shepherd

\section{Multimedia Conferencing, Synchronization and Multicast}

Fast and Optimal Multicast-Server Selection Based

on Receivers' Preference

Akihito Hiromori, Hirozumi Yamaguchi, Keiichi Yasumoto, Teruo Higashino, and Kenichi Taniguchi

Mcast: A Multicast Multimedia Communication Software

Development Platform.

Chung-Ming Huang and Hsu-Yang Kung

Enforcing Multipoint Multimedia Synchronisation in

Videoconferencing Applications

Philippe Owezarski

\section{Communication, Control and Telephony over IP Networks}

Utility-Based Inter-stream Adaptation of Layered Streams in a Multiple-Flow

IP Session

Dimitros Miras, Richard Jacobs, and Vicky Hardman

An Interaction Control Architecture for Large Chairperson-Controlled

Conferences over the Internet

Lukas Ruf, Thomas Walter, and Bernhard Plattner

Using DMIF for Abstracting from IP-Telephony Signaling Protocols

R. Ackermann, V. Darlagiannis, U. Roedig, and Ralf Steinmetz.

\section{Invited Presentation}

Short-Range Connectivity with Bluetooth.

Jaap C. Haartsen 


\section{QoS Models and Architectures}

A QoS-Control Architecture for Object Middleware

L. Bergmans, Aart van Halteren, L. Ferreira Pires, Marten J. van Sinderen, and M. Aksit

An Architecture for a Scalable Video-on-Demand Server Network with Quality-of-Service Guarantees

L.-O. Burchard and R. Lüling

Augmented Reliable Multicast CORBA Event Service (ARMS):

A QoS-Adaptive Middleware

João Orvalho and Fernando Boavida

Middleware Support for Media Streaming Establishment Driven

by User-Oriented QoS Requirements

Cristian Hesselman, Ing Widya, Aart van Halteren, and Bart Nieuwenhuis

\section{Multimedia Applications and User Aspects}

Interaction of Video on Demand Systems with Human-Like Avatars

and Hypermedia

Norbert Braun and Matthias Finke

How to Make a Digital Whiteboard Secure - Using Java-Cards

for Multimedia Applications

Rüdiger Weis, Jürgen Vogel, Wolfgang Effelsberg, Werner Geyer, and Stefan Lucks

How to Keep a Dead Man from Shooting

Martin Mauve

Building Web Resources for Natural Scientists.

Paul van der Vet

\section{Invited Presentation}

On the Failure of Middleware to Support Multimedia Applications

Gordon S. Blair

\section{Design and Implementation Approaches}

JASMINE: Java Application Sharing in Multiuser INteractive Environments ..... 214

Abdulmotaleb El Saddik, Shervin Shirmohammadi, Nicolas D. Georganas, and Ralf Steinmetz

Design and Implementation of a Framework for Monitoring Distributed

Component Interactions

Nikolay K. Diakov, Harold J. Batteram, Hans Zandbelt, and Marten J. van Sinderen Specification and Implementation of an Extensible Multimedia System ..... 241 Jürgen Hauser and Kurt Rothermel 
Communication Protocol Implementation in Java. 254

Gyula Csopaki, Gábor András Horváth, and Gábor Kovács

\section{Mobile Multimedia and Ubiquitous Computing Systems}

Active Component Driven Network Handoff for Mobile Multimedia Systems ...... 266

Stefan Schmid, Joe Finney, Andrew Scott, and Doug Shepherd

"Mix and Match" Media Servers

Mauricio Cortes and J. Robert Ensor

Spatially Aware Local Communication in the RAUM System

Felix Hupfeld and Michael Beigl

The UbiCampus Project: Applying Ubiquitous Computing Technologies in a University Environment.

C. Müller-Schloer and P. Mähönen

Author Index 